NASA Technical Memorandum 103164

\title{
High Frequency, High Temperature Specific Core Loss and Dynamic B-H Hysteresis Loop Characteristics of Soft Magnetic Alloys
}

W.R. Wieserman

University of Pittsburgh at Johnstown

Johnstown, Pennsylvania

G.E. Schwarze

National Aeronautics and Space Administration

Lewis Research Center

Cleveland, Ohio

and

J.M. Niedra

Sverdrup Technology, Inc.

Lewis Reseach Center Group

Brook Park, Ohio

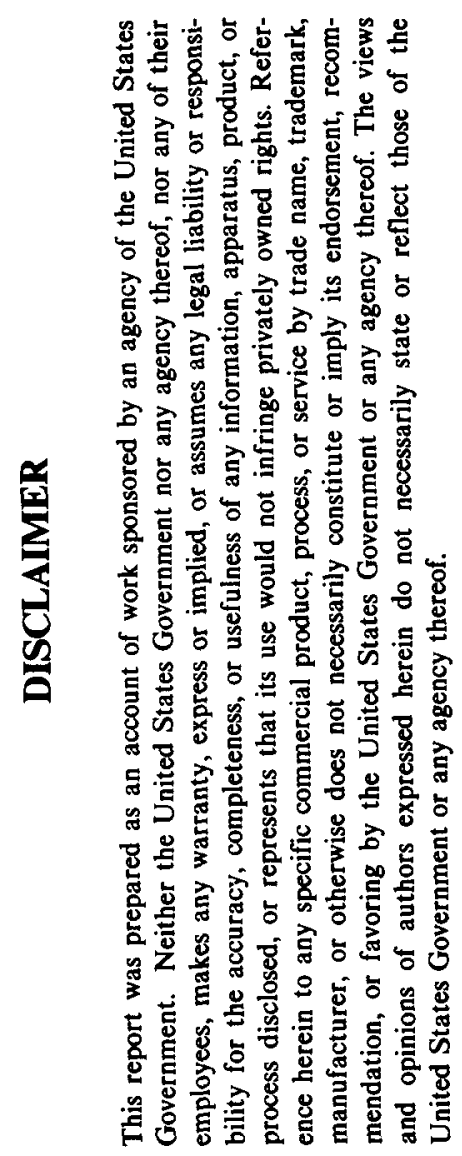

Prepared for the

25th Intersociety Energy Conversion Engineering Conference cosponsored by the AIChE, SAE, ACS, AIAA, ASME, and IEEE Reno, Nevada, August 12-17, 1990

\section{N/Sn}




\section{DISCLAIMER}

This report was prepared as an account of work sponsored by an agency of the United States Government. Neither the United States Government nor any agency Thereof, nor any of their employees, makes any warranty, express or implied, or assumes any legal liability or responsibility for the accuracy, completeness, or usefulness of any information, apparatus, product, or process disclosed, or represents that its use would not infringe privately owned rights. Reference herein to any specific commercial product, process, or service by trade name, trademark, manufacturer, or otherwise does not necessarily constitute or imply its endorsement, recommendation, or favoring by the United States Government or any agency thereof. The views and opinions of authors expressed herein do not necessarily state or reflect those of the United States Government or any agency thereof. 


\section{DISCLAIMER}

Portions of this document may be illegible in electronic image products. Images are produced from the best available original document. 
HIGH FREQUENCY, HIGH TEMPERATURE SPECIFIC CORE LOSS AND DYNAMIC

B-H HYSTERESIS LOOP CHARACTERISTICS OF SOFT MAGNETIC ALLOYS

W.R. Wieserman

University of Pittsburgh at Johnstown

Johnstown, Pennsylvania 15902

\author{
G.E. Schwarze \\ National Aeronautics and Space Administration \\ Lewis Research Center \\ Cleveland, Ohio 44135
}

\author{
J.M. Niedra \\ Sverdrup Technology, Inc. \\ Lewis Research Center Group \\ Brook Park, Ohio 44142
}

\begin{abstract}
Limited experimental data exists for the specific core loss and dynamic B-H loops for soft magnetic materials for the combined conditions of $h$ igh frequency and high temperature. This experimental study investigates the specific core loss and dynamic B-H loop characteristics of Supermalloy and Metglas $2605 \mathrm{SC}$ over the frequency range of $1-50 \mathrm{kHz}$ and temperature range of 23-300 C under sinusoidal voltage excitation. The experimental setup used to conduct the investigation is described. The effects of the maximum magnetic flux density, frequency, and temperature on the specific core loss and on the size and shape of the B-H loops are examined.
\end{abstract}

\section{INTRODUCTION}

The Power Conditioning, Control, and Transmission (PCC\&T) subsystem of future high power space systems will need to meet the requirements of high efficiency, low specific mass and high reliability. To meet these requirements, the power and control components for the PCC\&T will need to operate at high frequencies to reduce the reactive-type component masses and at high temperatures to reduce the size of the cooling radiator. The magnetic component designer will need to know the high temperature and high frequency performance characteristics of soft magnetic materials in order to design and develop components such as transformers, inductors, and motors for the PCC\&T subsystem, and power generators for the electrical conversion subsystem. Magnetic components for sensors and instrumentation in the control subsystem will also need this high frequency and high temperature magnetic data.

Under the Power Management[1] element of the Civilian Space Technology Initiative (CSTI) High Capacity Power Program an experimental program has been initiated by the NASA-Lewis Research Center to characterize the electrical and magnetic properties of soft ferromagnetic materials under various operating conditions. A survey of the literature prior to the program's initiation clearly showed a sparsity of electrical and magnetic data for soft magnetic materials under the combined effects of high temperature and high frequency. Thus, the objective of this experimental program is to investigate candidate commercially available magnetic materials up to $50 \mathrm{kHz}$ and temperatures to $300 \mathrm{C}$ under both sinusoidal and non-sinusoidal voltage excitation. The materials to be investigated include alloys of nickel-iron, cobalt-iron, and silicon-iron and the new class of amorphous alloys. This paper gives the high frequency, high temperature results for two different soft magnetic materials. The measuring, computing, and plotting system developed to experimentally determine the specific core loss and dynamic B-H hysteres is loop characteristics under sinewave voltage excitation of these two materials is also described.

\section{EXPERIMENTAL SYSTEM}

The circuit diagram in Figure I shows the experimental setup used to measure, compute, plot, and display the electrical and magnetic characteristics of the test core material. Two key elements in this setup are the digital storage oscilloscope and the power amplifier. A high slew rate, high frequency, variable-amplitude power amplifier having very low amplitude and phase distortion is a necessity if the amplifier's output drive signal is to faithfully reproduce the waveshape of the oscillator's input signal. The digital storage oscilloscope along with the system controller replaces the wattmeter that is generally used for core loss measurements. Significant improvements have been made in high frequency wattmeters but they still have limitations, especially for the condition of non-sinusoidal core excitation. The digital oscilloscope used in this investigation provides a sampling rate of 20 megasamples persecond, an equivalent-time bandwidth of $400 \mathrm{MHz}$, and 14-bit vertical resolution in the signalaveraging mode.

Thottuvelil, et al [2,3] have developed a high frequency measuring system which uses a digital oscilloscope to obtain core loss and B-H loop characteristic data. The setup in Figure 1 has many features similar to $[2,3]$.

In Figure 1 the output of the oscillator is connected to a frequency counter and the input of the power amplifier which provides the voltage excitation to the primary winding $N_{p}$ of the test core. A coaxial current-sensing resistor trimmed to give $R_{c}=0.10$ ohms is connected between $N p$ and the low side of the amplifier. The excitation or primary current $i_{p}(t)$ is sensed by measuring the voltage drop across $R_{c}$. The voltage $e_{s}(t)$ induced in the secondary winding $N_{s}$ is used to sense the changing flux. $i_{p}(t)$ and $e_{s}(t)$ are captured, 
digitized and stored in the digital oscilloscope and then transferred to the system controller for further processing and plotting.

A high temperature oil bath with its integrated controller regulates the test core's temperature environment. This bath is filled with a special high temperature silicone oil into which the test cores are immersed. Local heating of the cores, particularly for the test condition of high flux density at high frequency, is reduced by circulating the silicone oil. Precautions were taken to prevent local heating under all test conditions. Uniform heating of the core is the desired condition, otherwise the material's electrical and magnetic characteristics can be adversely affected and thus, possibly lead to incorrect interpretations of the experimental data.

By Ampere's Law the magnetizing field strength $H(t)$ is given by

$$
H(t)=\frac{N_{p} I_{p}(t)}{T_{m}} \quad A / m
$$

where $l$ is the mean path length of the magnetic core. Under the assumption that $N_{s}$ has a negligible voltage drop, it follows from Faraday's Law that

$$
e_{8}(t)=N_{8} A_{c} \frac{d B(t)}{d t} \quad V
$$

where $B(t)$ is the instantaneous flux density in the core material and $A_{c}$ is the magnetic crosssectional area of the core. Integration of $\mathrm{Eq}$. (2) gives

$$
B(t)=\frac{1}{N_{s} A_{c}} \int e_{s}(t) d t \quad T \quad(3)
$$

By means of Eqs. (1) and (3) the dynamic B-H loop can be plotted. The area enclosed by the B-H loop is a graphical representation of the core loss, but more importantly, the size and shape of the loop gives a very good visual display of how the test core characteristics change as a function of temperature, frequency, excitation and core geometry. The B-H loop also provides additional information such as the remanence and coercivity points.

The instantaneous power $p(t)$ dissipated by the magnetic material is

$$
p(t)=\left(\frac{N_{p}}{N_{s}}\right) \quad i_{p}(t) e_{s}(t), \quad w
$$

The time average of $p(t)$ over one period of either $i_{p}(t)$ or $e_{s}(t)$ gives the core loss. $e_{s}(t)$ was chosen because it provided well defined zero crossings for determining the period. The specific core loss is the core loss divided by the core mass.

\section{MATERIALS AND TEST CORE DESCRIPTION}

The soft magnetic materials selected for this investigation were Supermalloy $(79 \% \mathrm{Ni}, 17 \% \mathrm{Fe}, 4 \%$ Mo) and Metglas $2605 \mathrm{SC}$ (81\% Fe, 13.5\% B, 3.5\% Si,
$2 \%$ C). According to reference 4, Supermalloy has a range of maximum flux density between 0.65 and $0.82 \mathrm{~T}$, a Curie temperature of $460 \mathrm{C}$ and a mass density of $8.7 \mathrm{gms} / \mathrm{cm}_{3}$. This same reference states that Metglas 2605SC has a range of maximum flux density between 1.5 and $1.6 \mathrm{~T}$, a Curie temperature of $370 \mathrm{C}$ and a mass density of $7.32 \mathrm{gms} / \mathrm{cm}_{3}$.

The magnetic core geometry was a toroid wound from 0.001 inch thick by 0.25 inch wide tape with nominal dimensions of I.D. $=1.0$ inch and $0 . D .=1.25$ inches. The toroids were supplied by the manufacturer in unsealed core cases and without damping material. The magnetic cores were removed from the aluminum cases for measuring their mass and cross-sectional area. The core mass was measured with an analytical balance and the core cross-sectional area was measured with a micrometer. The epoxy impregnated fibrous washer normally used for sealing the aluminum case during manufacturing was replaced with Teflon fabricated washers. The size of these washers was such that they rested on the outer edges of the open end of the aluminum case and no contact existed between the magnetic core and washer.

Each test core was prepared by placing the magnetic core in the aluminum core case, covering the open end with the Teflon washers and then wrapping the assembly with several layers of high temperature mica impregnated tape. The mica tape provided the necessary electrical insulation between the core case and the windings. The primary and secondary windings were wound on the insulated assembly using a high temperature (Class 220) magnet wire Even though the test cores were tested up to $300 \mathrm{C}$, no electrical breakdown of the insulation was detected. Each core was fully immersed in the oil while suspended by its leads from a Teflon terminal board mounted above the bath. A set of three cores of the same core material was prepared for each data run. Separate data runs were made for each material.

\section{EXPERIMENTAL RESULTS}

The specific core loss (SCL) as a function of maximum flux density $B_{m}$ with frequency $f$, temperature, excitation and tape thickness as parameters, is shown for Supermalloy in Figure 3a and for Metglas 2605SC in Figure 3b. Each figure gives four sets of curves with three curves for each set. The sets are for the frequencies of 5 , 10,20 and $50 \mathrm{kHz}$ and the three curves within each set are for the temperatures of 23,150 and $300 \mathrm{C}$. The data given in Figures 3,4 and 5 are for a single core and are representative of the results obtained for 3 cores of that particular material.

Figures 4 and 5 show the frequency-nested set of B-H loops for Supermalloy and Metglas 2605SC, respectively. If an examination of the temperature effects on the size and shape of a particular frequency loop is desired, then the frequencynested loops for that material must be plotted for the same B. The Bm used for these B-H plots was selected on the basis of the highest value of $B m$ obtainable over the range of frequencies and temperatures tested. 
The $B-H$ Supermalloy loops in Figure $4 a(23 \mathrm{C})$ and Figure $4 b(300 \mathrm{C})$ are all plotted for $B=0.4 \mathrm{~T}$ and $f=1 \mathrm{kHz}$ (inner 10op), 5, 10, 20, and $50 \mathrm{kHz}$ (outer loop). Both figures show that the loop area increases with frequency, particularly from 20 to $50 \mathrm{kHz}$. Comparison of these two figures shows how temperature affects the loop's size and shape characteristics. The shape of the $300 \mathrm{C}$ loops indicate flux saturation while the elliptical shaped $23 \mathrm{C}$ loops indicate non-saturation. For a given frequency, the enclosed area or size of a 300 $C$ loop is always larger than a 23 C loop. This result is unexpected since the loss is expected to decrease with temperature [4]. Since these test cores experienced prolonged heating at $100 \mathrm{C}$ and above, i.e. see Figure $2 a$, it is possible that the cause is due to temperature ageing effects. The effects of temperature ageing on this material will require additional investigation.

The Metglas 2605SC loops in Figure $4 \mathrm{a}(23 \mathrm{C})$ and Figure $5 b(300 \mathrm{C})$ are plotted for $B_{m}=0.8 \mathrm{~T}$ and $f=1$ $\mathrm{kHz}$ (inner loop), 5, 10, 20, and $50 \mathrm{kHz}$ (outer loop). Comparison of these figures shows that the loop size increases with frequency for each temperature and decreases in size with temperature for each frequency. These are the expected results. The temperature-time profile for the Metglas 2605SC test cores is shown in Figure $2 b$.

\section{DISCUSSION}

Each of the two magnetic materials investigated clearly showed the effect of maximum flux density, frequency, and temperature on the specific core loss. The curves in Figures $3 a$ and $3 b$ show the expected tendency for the SCL to increase as either $B_{m}$ or $f$ increases. However, for both materials, the expected tendency for the SCL to decrease for an increase in temperature for a given $\mathrm{Bm}$ and $f$ did not always hold true.

Clark and Fritz [5] investigated Supermalloy for $f=60,400$ and $1000 \mathrm{~Hz}$ over a temperature range of $-55 \mathrm{C}$ to $250 \mathrm{C}$ and found that an increase in temperature caused a decrease in the $\mathrm{SCL}$. In this investigation of Supermalloy it was found that for a given $B$ and $f$, the $S C L$ did indeed decrease from $23 \mathrm{C}$ to $158 \mathrm{C}$ but then increased from $150 \mathrm{C}$ to 300 C so that the $\mathrm{SCL}$ is greater at $300 \mathrm{C}$ than at 23 C. It is felt, as previously noted, that a possible cause for this increase in SCL from $150 \mathrm{C}$ to $300 \mathrm{C}$ is temperature ageing effects. If indeed, Supermalloy is susceptible to temperature ageing effects, then the cause and rate of this effect must be determined if this material is to be considered for high temperature applications. The $\mathrm{SCL}$ for the other two Supermalloy cores tested showed the same trends as the curves in Figure $3 a$. The effect of temperature on the SCL for Metglas 2605SC follows the normal pattern of showing a decrease in SCL for an increase in temperature with the following exception. For $B \leq 0.2 \mathrm{~T}$ and $f=5,10$ and $20 \mathrm{kHz}$, the $\mathrm{SCL}$ is slightly higher at $150 \mathrm{C}$ than at $23 \mathrm{C}$. Similar SCL results were found for the other two Metglas 2605SC cores tested.

A comparison of Supermalloy and Metglas 2605SC shows that Supermalloy gives a lower SCL than
Metglas 2605SC for comparable values of $B, f$, and temperature. For example, at $B=0.4 \mathrm{~T}, f=28 \mathrm{kHz}$ and $T=150 \mathrm{C}$, the $\mathrm{SCL}$ is $16 \mathrm{~W} / 1 \mathrm{~b}$ for Supermalloy and 60 $w / 1 b$ for Metglas 2605SC. For this same $B$ and $f$ at $T=300 \mathrm{C}$, the $S C L$ is $21 \mathrm{~W} / \mathrm{lb}$ for Supermal $\mathrm{Poy}$ and 30 W/lb for Metglas $2605 S C$.

\section{ACKNOWLEDGMENT}

This research was sponsored by the NASA Lewis Research Center under the High Capacity Power Element of the Civilian Space Technology Initiative.

\section{REFERENCES}

1. Schwarze, G. E., "Overview of Space Power Electronics Technology Under the CSTI High Capacity Power Program", Proceedings Seventh Symposium on Space Nuclear Power Systems, Conf-900109, Albuquerque, New Mexico, January $7-10,1990$.

2. Thottuvelil, V. J., Wilson, T. G. and Owens, H. A., Jr., "High-Frequency Measurement Techniques for Magnetic Cores", IEEE Power Electronics Specialists Conference, June 1985, Dp 412-425.

3. Thottuvelil, V. J., Wilson, T. G., Miyazaki, I. and Owens, H. A., Jr., "High-Frequency Characteristics of Amorphous Metallic-Alloy Tape-Wound Cores", IEEE Power Electronics Specialists Conference, June 1983, PP 168180.

4. "Design Manual Featuring Tape Wound Cores", TWC-300T, Magnetics Components Division, Butler, Pennsylvania, 1987, p 14.

5. Clark, J. J. and Fritz, J. F., "The Effect of Temperature on the A-C Magnetic Properties of Nickel-Iron Alloys", Wright Air Development Center Technical Note 58-277, WrightPatterson Air Force Base, Ohio, August 1958. 


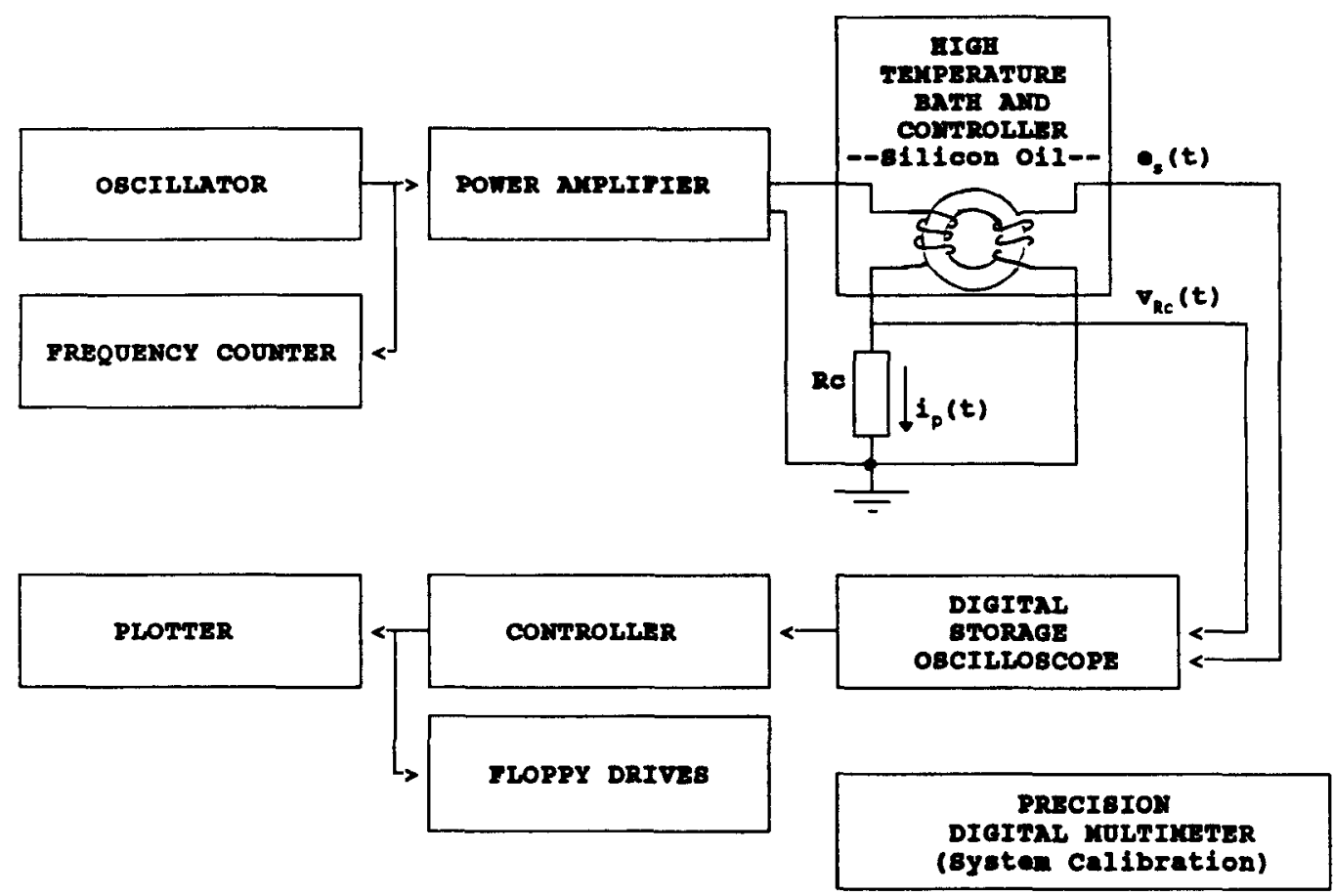

FIGURE 1. - SPECIFIC CORE LOSS AND B.H LOOP MEASUREMENT SYSTEM.

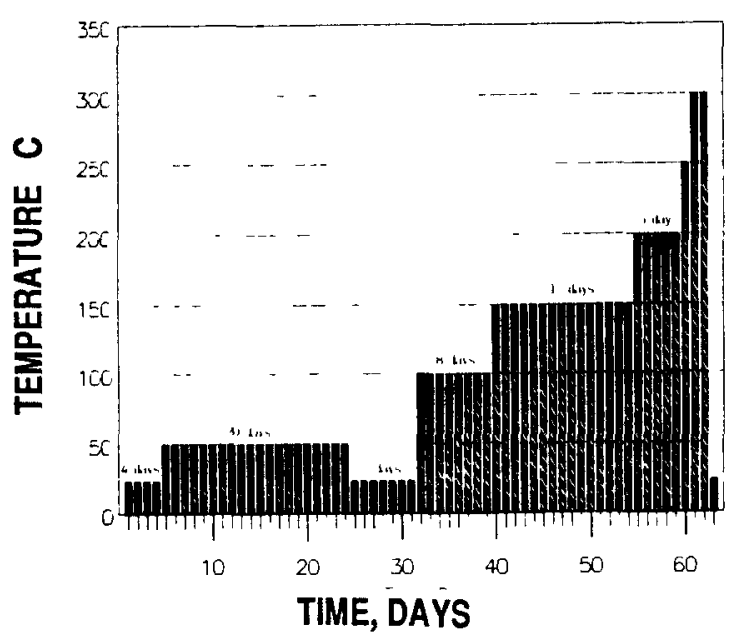

(a)

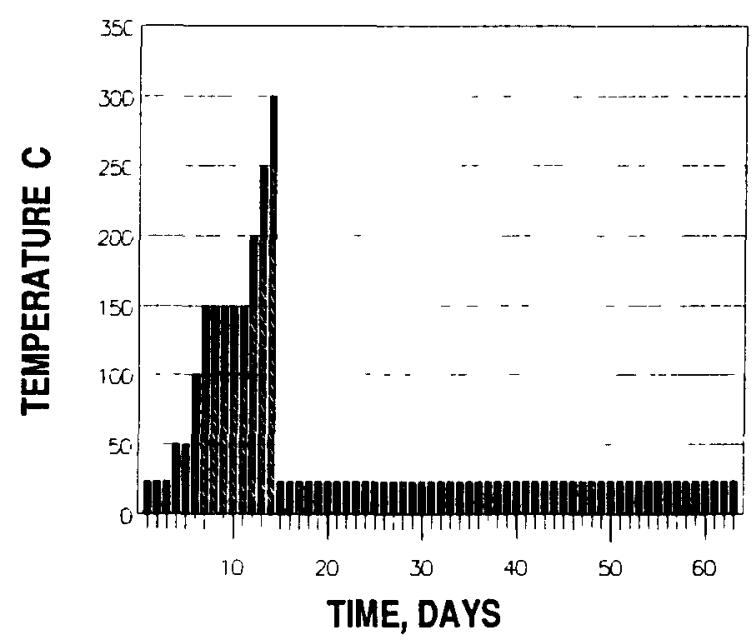

(b)

FIGURE 2. - TEMPERATURE HISTORY FOR TIME TEST CORES WERE HELD AT FIXED TEMPERATURE. (a) SUPERMALLOY, (b) METGLAS 2605SC. 


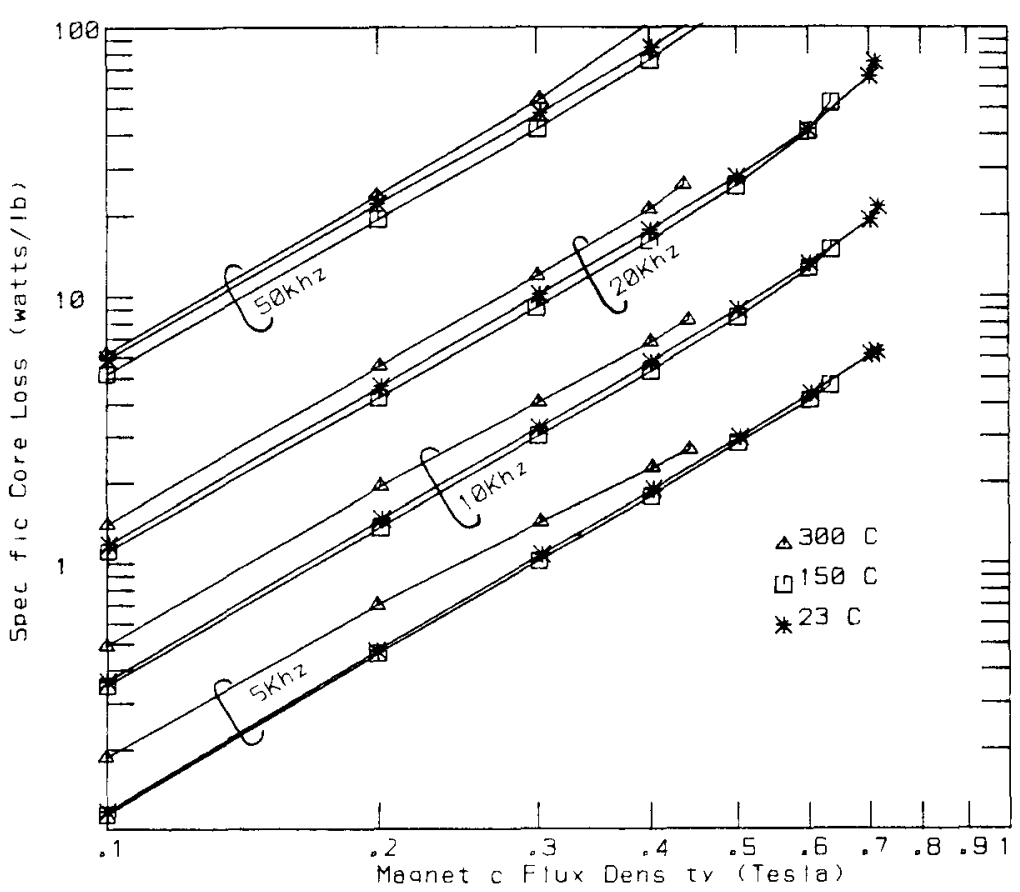

(a)

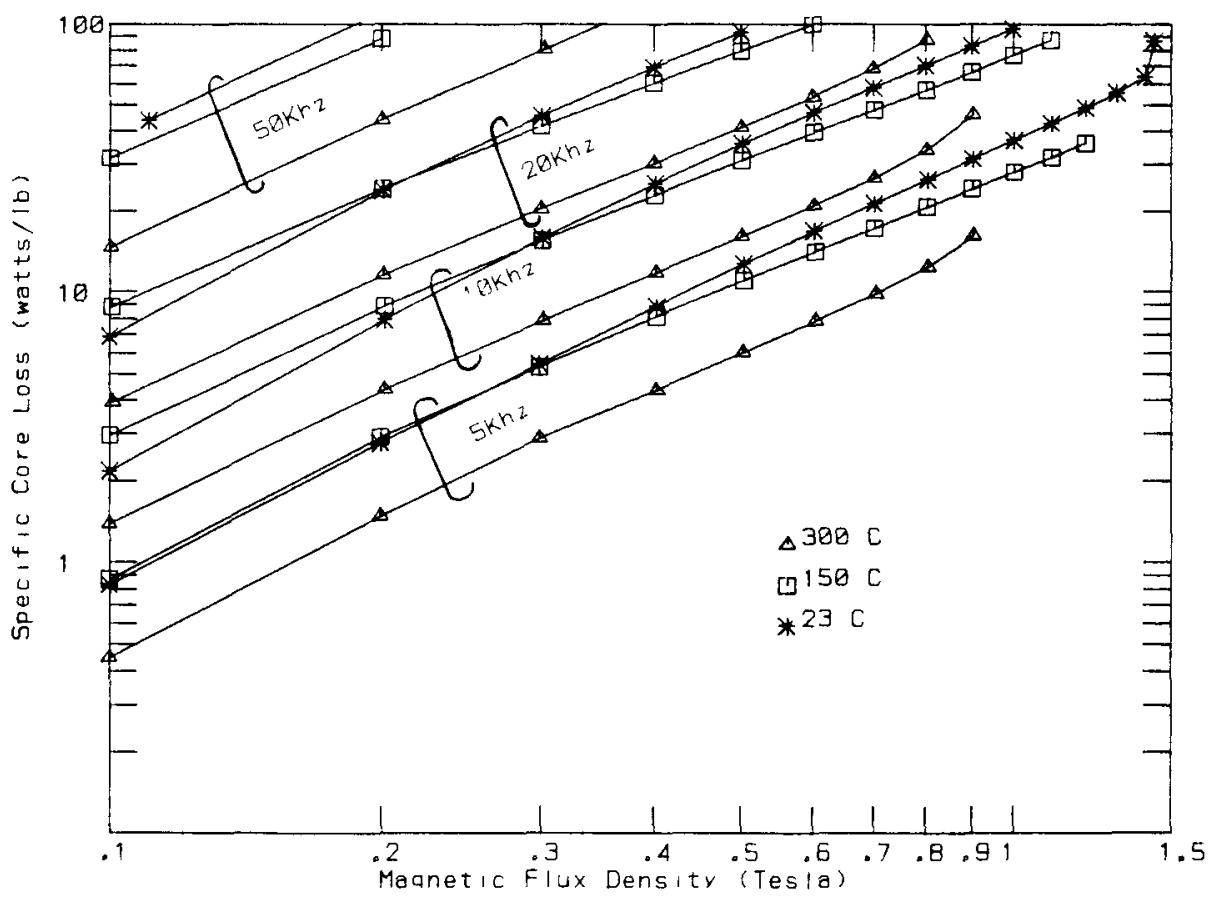

(b)

FIGURE 3. - SPECIFIC CORE LOSS VERSUS FLUX DENSITY WITH FREQUENCY AND TEMPERATURE AS PARAMETERS FOR SINEWAVE VOLTAGE EXCITATION. (a) SUPERMALLOY (TEST CORE 1FO7), (b) METGLAS $2605 S C$ (TEST CORE 1B03). 

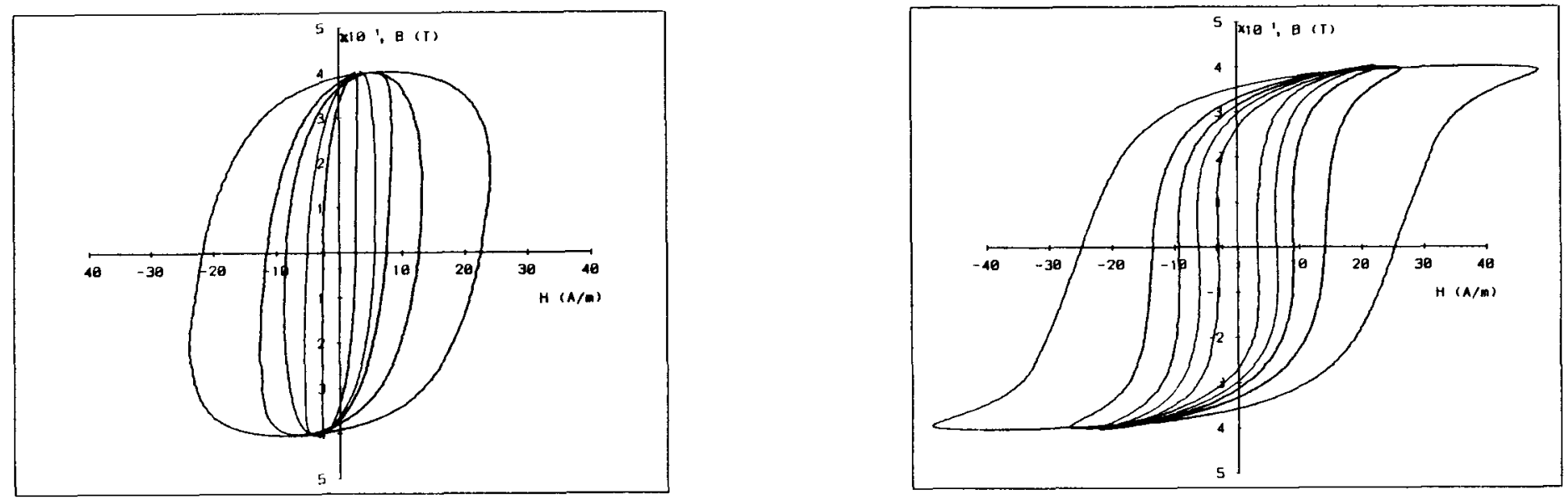

FIGURE 4. - B-H LOOPS OF SUPERMALLOY FOR BM $=0.4 T$ AND SINEWAVE VOLTAGE EXCITATION AT $\mathrm{f}=1 \mathrm{kHz}$ (inner loop), 5, 10, 20 AND $50 \mathrm{kHz}$ (outer loop).
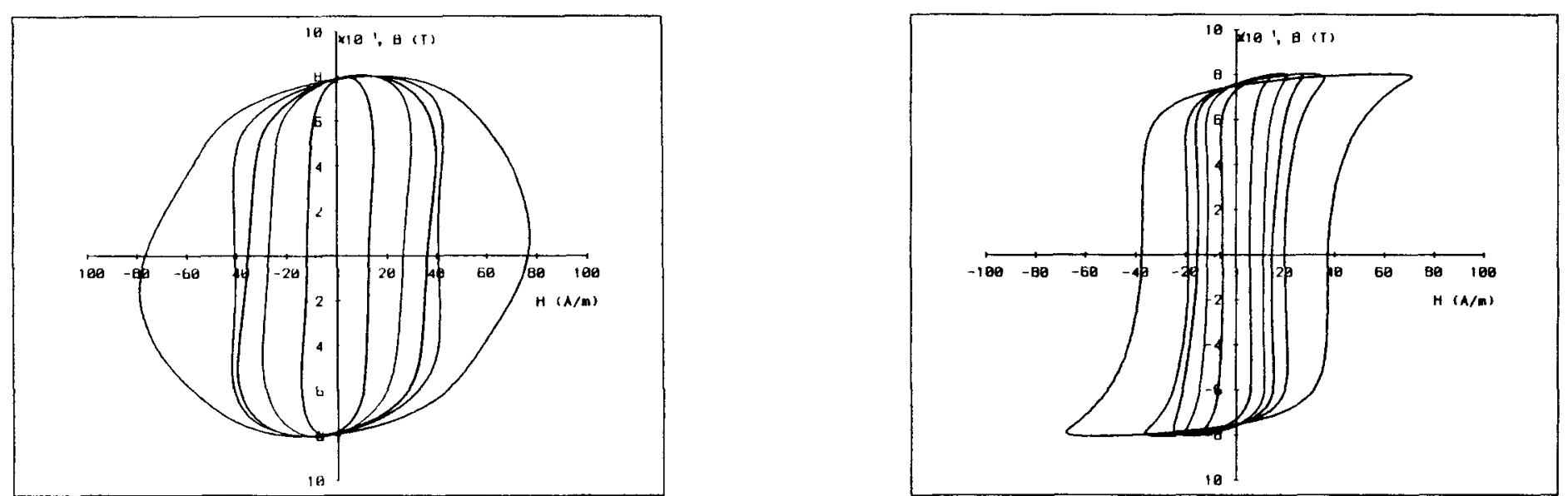

FIGURE 5. - B-H LOOPS OF METGLAS 2605SC FOR BM $=0.8 T$ AND SINEWAVE VOLTAGE EXCITATION AT $\mathrm{f}=1 \mathrm{kHz}$ (inner loop), $5,10,20$ and $50 \mathrm{kHz}$ (outer loop). (a) $23 \mathrm{C}$, (b) $300 \mathrm{C}$. 


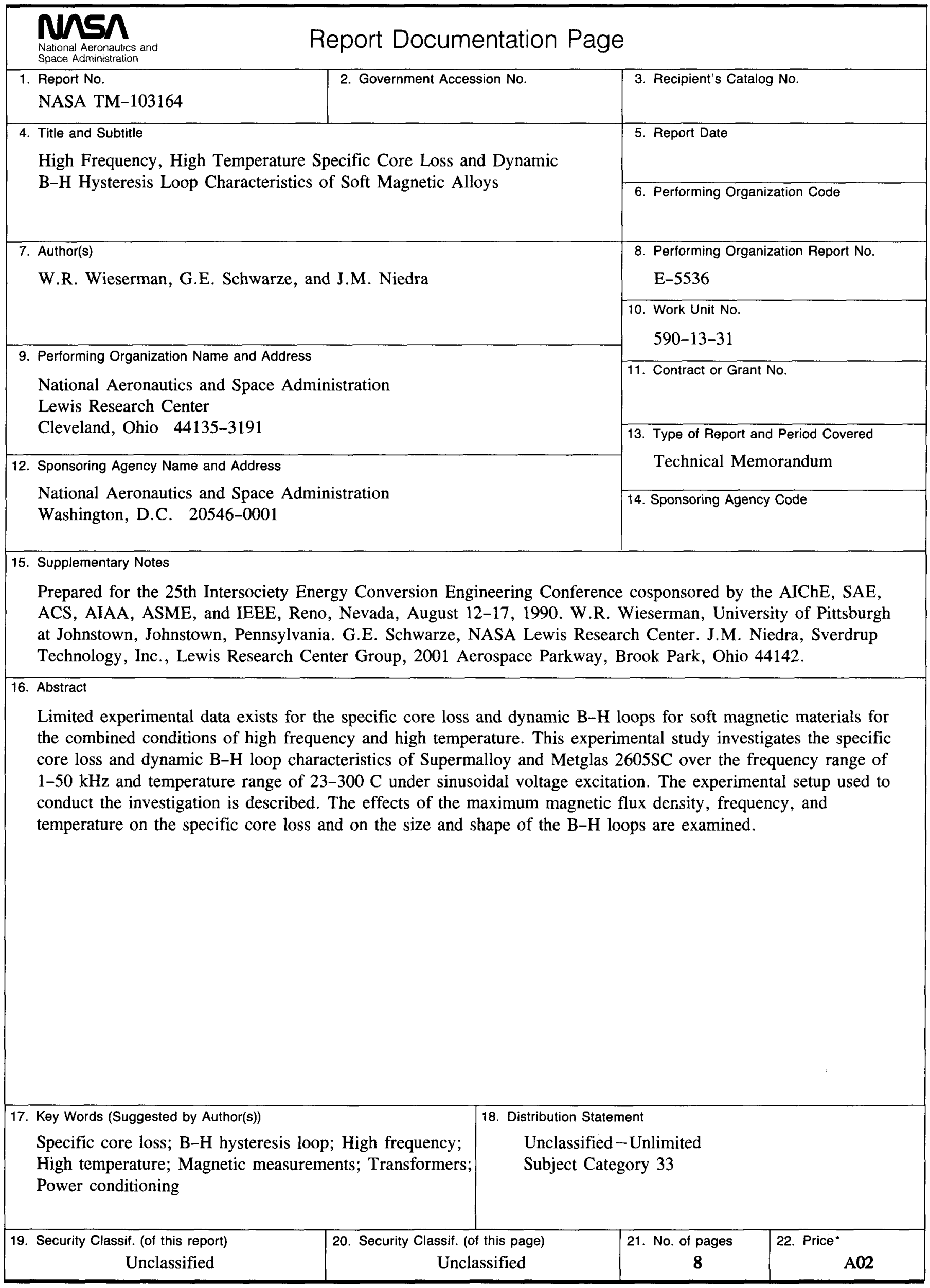

